when there is daytime somnolence or excessive nocturnal snoring, and to assess it properly requires polygraphic nocturnal monitoring.

We thank Professor W R Butt for the growth hormone assays; the technicians of the departments of clinical neurophysiology and respiratory physiology; and Mrs B Cartlidge for secretarial help. We are grateful to Mr A Lawton for statistical advice.

Requests for reprints to: Dr W van't Hoff, Department of Endocrinology, North Staffordshire Royal Infirmary, Stoke on Trent ST4 7LN.

\section{References}

1 Evans CC, Hipkin LJ, Murray GM. Pulmonary function in acromegaly. Thorax 1977;32:322-7.

${ }^{2}$ Phillipson EA. Control of breathing during sleep. Am Rev Resp Dis 1978;118:909-39.
${ }^{3}$ Guilleminault C, Van den Hoed J, Mitler MM. Clinical review of the sleep apnea syndromes. In: Guilleminault C, Dement WC, eds. Sleep apnea syndromes. New York: Academic Press, 1978:1-12.

4 Guilleminault C, Van den Hoed J. Acromegaly and narcolepsy. Lancet 1979 ;ii :750-1.

5 Barnes AJ, Pallis C, Joplin GF. Acromegaly and narcolepsy. Lancet 1979, ii:332-3.

- Rechtshaffen A, Kales A. Manual of standardized terminology, techniques and scoring system for sleep stages of human subjects. Bethesda, Maryland: National Institute of Neurological Disease and Blindness, 1968.

7 Seigel S. Non-parametric statistics for the behavioral sciences. New York: McGraw-Hill, 1956.

8 Tilkian AG, Motta J, Guilleminault C. Cardiac arrhythmias in sleep apnea. In: Guilleminault C, Dement WC, eds. Sleep apnea syndromes. New York: Academic Press, 1978:197-210.

9 Rees PJ, Ayres JG. Acromegaly and narcolepsy. Lancet 1979;ii:524-5.

${ }^{10}$ Cotes JE. Lung function: assessment and application in medicine. Oxford: Blackwell Scientific Publications, 1975.

(Accepted 28 fanuary 1980)

\title{
Management of acute illness in infants before admission to hospital
}

\author{
A N STANTON, P M McWEENY, A L JAY, E IRWIN, J R OAKLEY
}

\begin{abstract}
Summary and conclusions
Parents and family doctors were questioned about the management of 150 infants with acute illness before their admission to hospital. When 108 of the children were first assessed the family doctor did not consider that admission was necessary, but follow-up was arranged in only 14 of these cases. Thus in 94 cases the initiative for recall was left to the parents, who in 44 cases already wanted their child to be admitted. Forty-eight infants were referred because the doctors thought that the parents could not cope. The parents of 31 of the children delayed in seeking help.

As over half the children were ill for more than three days before they were admitted to hospital, regular follow-up could have been arranged. Doctors should normally retain the initiative for this rather than leave it to the parents' discretion.
\end{abstract}

\section{Introduction}

The classical symptoms of the acute life-threatening illnesses seen in infants presenting at hospital for admission are well documented. Less is known about the earlier symptoms, which may alert parents to the onset of their child's illness or to deterioration despite medical advice or treatment. The pre-

\footnotetext{
Department of Paediatrics, Northampton General Hospital, Northampton

A N STANTON, BM, MRCP, senior registrar

Children's Hospital, Western Bank, Sheffield S10 2TH

P M MCWEENY, research associate, University of Sheffield

A L JAY, MB, DCH, registrar in accident and emergency

E IRWIN, research associate, University of Sheffield

J R OAKLEY, MRCP, DCH, independent research worker, University of Sheffield
}

liminary results of a multicentre study of postperinatal mortality carried out by the Department of Health and Social Security suggested that almost half the children dying at home had had major symptoms in the last 48 hours of life and that these deaths, although not expected by the families and family doctors, were not necessarily unpredictable from the symptoms described. ${ }^{1}$ The illnesses had usually not developed particularly quickly, but many children had not been medically assessed. A minority had been seen-some more than once-by a doctor who had not appreciated the full or potential seriousness of the illness; follow-up had rarely been arranged. As we concluded that some of these children might have survived had the importance of their symptoms been recognised and appropriate medical aid sought and provided, we carried out a study of children who were acutely ill on admission to hospital and survived. We sought to identify the symptoms that had led the parents to seek medical consultations and to examine the management of children referred to family doctors before admission.

\section{Methods}

Information about 150 children aged under 12 months who were admitted to hospital while acutely ill and survived was obtained from studies in Sheffield and Gateshead between November 1977 and April 1978. Seventy-two children were from Sheffield and 78 from Gateshead. The Gateshead series comprised consecutive admissions to the Queen Elizabeth Hospital, the only hospital within the area health authority admitting paediatric emergencies. Only one family refused to be interviewed. The Sheffield series was compiled by weekly rotation of interviews between the three hospitals in the city that accepted acute admissions.

During 1977, 228 general practitioners covered the city of Sheffield, which had a mid-year population of 547400 and in which 5457 births occurred. Ninety-nine general practitioners covered Gateshead, which had a mid-year population of 217500 and 3264 births.

All the children had major symptoms, defined as those requiring a medical opinion on the same day and continuing close supervision. ${ }^{1}$ 
These included fever, wheezing, altered breathing, cough, diarrhoea, vomiting, missing feeds, unusual drowsiness, irritability, and an altered character to the cry. A single vomit, loose motion, or missed feed was not considered to be a major symptom. All children were eligible for inclusion if they were admitted after emergency referral from the primary care services or casualty departments, except when the cause of referral was trauma or poisoning or a major chronic disorder had previously been identified. Parents were interviewed by using a standard proforma, and information was generally obtained while the child was still in hospital, although short admissions were followed up at home. Detailed inquiries were made about the previous health and development of the child, and a full history obtained of the illness necessitating admission. A standardised telephone interview with the referring doctor was sought where appropriate. The doctor was asked about the nature and duration of the illness; about the symptoms and physical signs; whether advice had been sought at the appropriate time; and why it was decided that the child needed to be admitted.

\section{Results}

Similar patterns of illness and medical management were seen in Sheffield and Gateshead, and we therefore considered the two areas together. The table gives the ages of the infants on admission.
Thirty-four $\left(23^{\circ}{ }_{0}\right)$ of the families expressed hesitation about calling their family doctor, almost invariably alleging an obstructive receptionist or the practice's unwillingness to make home visits.

\section{Discussion}

Most parents with acutely ill infants turned to their family doctor for guidance, and the consultation generally resulted in a definitive medical opinion. Follow-up was usually left to the parents' discretion rather than the doctor's initiative, although the illnesses of half the children evolved for at least three days before admission to hospital became appropriate. At the first consultation the doctors did not consider admission to be necessary in 108 of the 150 cases, but only 14 follow-up appointments were made. Review of the remainder depended on the judgment of the parents, although 41 of the 94 families thought that their child should have been admitted after an earlier consultation. The parents were not always objective or correct in thinking that admission was necessary, but, even if they had been wrong in calling the doctor initially, they should not have been expected to choose the moment at which medical opinion would agree with their own.

Should the initiative for medical reassessment be left with

Age distribution of 150 infants admitted to hospital with acute illness

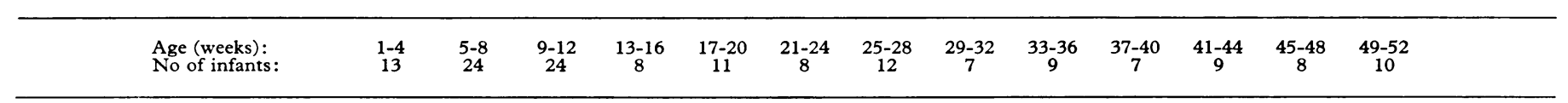

The following symptoms were those reported most commonly by the parents in the week before admission: vomiting, 77 infants $(51 \%)$; diarrhoea, $40(27 \%)$; cough, $92(61 \%)$; altered breathing, $50(33 \%)$; shortness of breath, $17(11 \%)$; wheeze, $19(13 \%)$; unusual drowsiness, $51(34 \%)$; missed feeds, $94(63 \%)$; irritability, $94(63 \%)$; altered cry, $34(23 \%)$; and fever, $26(17 \%)$. Most children had more than one symptom. The incidence of non-specific behavioural changes was high, especially unusual drowsiness, missed feeds, irritability, and an altered character to the cry. The duration of these major symptoms before admission was $0-24$ hours in 24 infants (16\%), $25-48$ hours in $24(16 \%), 49-72$ hours in $22(15 \%)$, and over 72 hours in $80(53 \%)$

Admission was requested by the primary care medical services in 117 of the 150 cases; the remainder were admitted from accident and emergency departments. The main reasons for referral from family doctors were obtained in 99 cases, and were: physical signs (26 infants), symptoms alone (16), illness not improving with treatment (9), parents unable to cope with the illness (46), and parental pressure (2). In 51 cases the severity of the illness was the crucial factor determining the doctor's decision to request admission. Within this group physical signs were emphasised more often than the symptoms reported by the family, and in 16 cases ( $31 \%$ ) the doctor thought that the parents should have sought help earlier in the illness. The remaining 48 children were not referred exclusively for medical reasons, but generally because the doctor considered the family to be unable to cope adequately with the illness.

The number of times each infant was seen by the family doctor before admission was as follows: not seen, 14 infants $(9 \%)$; once, $47(31 \%)$; twice, $47(31 \%)$; three times, $25(17 \%)$; four times, $13(9 \%)$; and five times or more, $4(3 \%)$. Fourteen children were taken direct to hospital without having seen the family doctor earlier in the illness. Of the remaining 136 children, 28 were admitted as the result of the first contact with the general practitioner; 14 after reassessment arranged by him; 75 after follow-up requested by the parents for reassessment; and 19 were taken direct to hospital by the parents after a consultation that did not result in admission. Thus when the general practitioners saw 108 of the infants they did not consider admission to be necessary; and in 94 of these cases $(87 \%)$ the initiative for further follow-up was left to the families. Forty-one of these families $(44 \%)$ stated that they had wanted their child admitted earlier in the illness, although they had rarely discussed this with the doctor. Eight families believed that they could have coped with their child's illness at home and that admission had been unnecessary. the parents? Whatever the ethics, our findings agree with those of a study of infant deaths in Glasgow ${ }^{2}$ in showing that this is not in the best interest of the child. We found that the general practitioners often thought that the parents had delayed too long in seeking help. Furthermore, in half the cases the doctor's decision to admit was largely determined by family and environmental considerations rather than the severity of the illness alone. These findings are consistent with those of a study of acute admissions to hospital throughout childhood, in which social factors were considered to be the main reason for admission in $20 \%$ of cases and a contributory reason in many others. $^{3}$

While many infants may be left to recover from apparently mundane illnesses, many are still dying at home from apparently similar illnesses that fail to improve or worsen. ${ }^{1}$ We consider that daily reassessment by a professionally qualified person should be normal practice when a child has major symptoms in the early months of life, with provision made for early recall or cancellation of this assessment. Some of this work may be left to health visitors, particularly if there is doubt about the family's ability to manage the illness. This study shows that if follow-up is not volunteered by the doctor most parents will continue to seek it. Their requests will often be made at times inconvenient for the doctor, and a home visit rather than a surgery appointment may be necessary. The child will often be seen by a doctor who does not know the earlier features of the illness.

Young children cannot explain that they feel ill, and behavioural changes are frequently their only warning signals before death. ${ }^{14}$ The importance of these symptoms reported to the doctor by the parents should not be underestimated or given secondary importance to physical signs. Parents are in the best position to judge changes in their child's behaviour, although they may not be able to interpret the importance of the changes. Careful history taking should promote parental confidence and establish a more rewarding communication between parents and doctors. Full discussion might define the circumstances under which a further consultation would be needed, with an ultimate saving in medical time as well as reduced hazard for the child. 
Responsibility for follow-up must not be transferred back to the parents lightly, but routine follow-up implies more consultations, and further research is needed to establish whether our definition of major symptoms would result in many extra consultations or admissions to hospital.

This study was supported by grants from the Department of Health. We are grateful to Dr M Downham for advice; Dr W Kell, Mrs J Herdman, and Mrs C Ruddick for help with the Gateshead interviews; the families, doctors, and ward staff for co-operating with the study; and Mrs W Scott and Mrs A Jowett for secretarial help.

\section{References}

${ }^{1}$ Stanton AN, Downham MAPS, Oakley JR, Emery JL, Knowelden J. Terminal symptoms in children dying suddenly and unexpectedly at home. Br Med F 1978;ii:1249-51.

${ }^{2}$ Richards IDG, McIntosh HT. Confidential inquiry into 226 consecutive infant deaths. Arch Dis Child 1972;47:697-706.

3 Wynne J, Hull D. Why are children admitted to hospital ? $\mathrm{Br}$ Med $\mathcal{F} 1977$; ii:1140-2.

4 Oakley JR, Stanton AN. Meningococcal infections during infancy: confidential inquiries into 10 deaths. $B r$ Med $\mathcal{F} 1979$;ii:468-9.

(Accepted 15 fanuary 1980)

\title{
Haemophilus influenzae type $B$ meningitis: a contagious disease of children
}

\author{
MARY P GLODE， ROBERT S DAUM， DONALD A GOLDMANN， JEANNE LECLAIR, \\ ARNOLD SMITH
}

\section{Summary and conclusions}

The families of 126 consecutive patients with Haemophilus influenzae type $B$ meningitis were surveyed for secondary invasive $H$ influenzae disease among household contacts. A total of 120 of the families were contacted. In six cases no contact was possible and the medical record was reviewed. Some 555 household contacts were found; $31 \%$ (171) were under 5 years of age. A secondary case was defined as a household contact with $H$ influenzae type $B$ isolated from blood or cerebrospinal fluid more than 24 hours, but less than 30 days, after admission to hospital of the index case. Four secondary cases were identified, all in children aged under 5 years. The secondary attack rate in children under 5 years or less in the month after exposure to an index case was thus $2 \cdot 3 \%, 800$ times the endemic attack rate for $H$ influenzae meningitis. This is a conservative estimate since five additional contact cases were documented, but not included in the secondary attack rate.

Young contacts of a child with $H$ influenzae meningitis are thus at significant risk of life-threatening secondary disease.

\section{Introduction}

Haemophilus influenzae type $\mathrm{B}$ remains the major cause of bacterial meningitis in infants and children in the United States: it is estimated that 10000 cases occur yearly. ${ }^{1}$ Unlike meningococcal disease, $H$ influenzae is generally not considered to be sufficiently contagious to warrant prophylaxis of contacts. Nevertheless, several lines of evidence suggest a need to reevaluate this recommendation. A high rate of carriage of

Division of Infectious Disease, Children's Hospital Medical Centre, Boston, Massachusetts

MARY P GLODE, MD, research fellow (now associate director of infectious disease, the Children's Hospital, Denver, Colorado)

ROBERT S DAUM, MD, research fellow (now assistant professor of paediatrics, Tulane University School of Medicine, New Orleans)

DONALD A GOLDMANN, MD, hospital epidemiologist and director of bacteriology

JEANNE LECLAIR, $M P H$, infection control practitioner

ARNOLD SMITH, MD, professor of paediatrics (now chief, Division of Infectious Disease, Children's Orthopaedic Hospital and Medical Centre, Seattle, Washington)
$H$ influenzae type $\mathrm{B}$ has been recognised for many years in families of index cases, and temporally related familial cases have been noted sporadically since $1909 .{ }^{2-11}$ Several clusters of cases of invasive $H$ influenzae type $\mathrm{B}$ disease have also been reported in day care centres. ${ }^{12-17} \mathrm{~A}$ secondary attack rate in families of $4 \%$ to $5 \%$ was recently suggested on the basis of a retrospective study, ${ }^{18}$ but only 220 families of 546 index cases were available for review and there was only one secondary case of $H$ influenzae type B disease proved by culture.

To determine the secondary attack rate more accurately we reviewed all cases of $H$ influenzae type $\mathrm{B}$ meningitis seen at the Children's Hospital Medical Centre, Boston, Massachusetts, over three years.

\section{Patients and methods}

All medical records of children admitted to the Children's Hospital Medical Centre from January 1975 to January 1978 and discharged with a diagnosis of $H$ influenzae type B meningitis were reviewed. One hundred and twenty-six records representing 127 cases were reviewed.

In the index cases $H$ influenzae type $\mathrm{B}$ meningitis had been established by isolating the organism on cerebrospinal fluid culture or by detecting type $B$ capsular polysaccharide in cerebrospinal fluid by latex agglutination ${ }^{19}$ in patients with clinical and laboratory data compatible with bacterial meningitis, but in whom antibiotic treatment had been started before the diagnosis of meningitis.

We aimed to identify any cases of $H$ influenzae type $\mathbf{B}$ meningitis that occurred among household or day care centre contacts of the index children. Secondary cases of invasive $H$ influenzae disease were those diagnosed (by isolation from blood or cerebrospinal, joint, or pleural fluid) in a contact of the index case more than 24 hours but less than 30 days after the index patient was admitted to hospital. Household contacts were defined as those people who spent four or more hours a day with the index patient in the week before the illness. Contacts from day care centres (any child care organisation catering for 10 or more children) were not counted as household contacts when calculating the secondary attack rate.

Approval for this study was obtained from the centre's committee on human investigation at Children's Hospital Medical Centre.

All charts were reviewed by one of the authors, who completed a questionnaire on clinical and bacteriological data. If the patient had a private physician we obtained his permission to contact the family. One of the authors contacted an adult in the family by telephone or letter and obtained the following information: $(a)$ names, ages, and sex of all people who normally lived in the house or who spent more than four hours a day with the index patient in the week preceding his or her admission to hospital; (b) whether index patient regularly attended a nursery, day care centre, or went to a babysitter's house; 